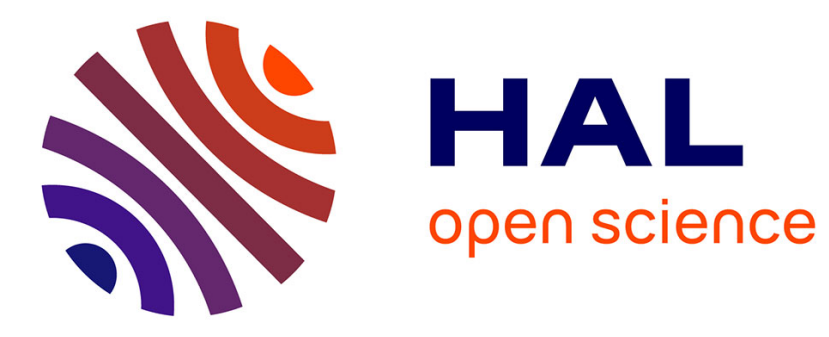

\title{
Identification of a geographic area characterized by extreme longevity in the Sardinia island
}

Michel Poulain, Giovanni Mario Pes, Claude Grasland, Ciriaco Carru, Luigi

Ferrucci, Giovannella Baggio, Claudio Franceschi, Luca Deiana

\section{- To cite this version:}

Michel Poulain, Giovanni Mario Pes, Claude Grasland, Ciriaco Carru, Luigi Ferrucci, et al.. Identification of a geographic area characterized by extreme longevity in the Sardinia island: the AKEA study. Experimental Gerontology, 2004, 39 (9), pp.1423-1429. 10.1016/j.exger.2004.06.016 . halshs$00175541 \mathrm{v} 2$

\author{
HAL Id: halshs-00175541 \\ https://shs.hal.science/halshs-00175541v2
}

Submitted on 22 Jun 2018

HAL is a multi-disciplinary open access archive for the deposit and dissemination of scientific research documents, whether they are published or not. The documents may come from teaching and research institutions in France or abroad, or from public or private research centers.
L'archive ouverte pluridisciplinaire HAL, est destinée au dépôt et à la diffusion de documents scientifiques de niveau recherche, publiés ou non, émanant des établissements d'enseignement et de recherche français ou étrangers, des laboratoires publics ou privés. 


\title{
Identification of a geographic area characterized by extreme longevity in the Sardinia island: the AKEA study
}

\author{
Michel Poulain ${ }^{\mathrm{a}, *}$, Giovanni Mario Pes ${ }^{\mathrm{b}}$, Claude Grasland ${ }^{\mathrm{c}}$, Ciriaco Carru ${ }^{\mathrm{b}}$, Luigi Ferrucci ${ }^{\mathrm{d}, \mathrm{e}}$, \\ Giovannella Baggio ${ }^{\mathrm{f}}$, Claudio Franceschi ${ }^{\mathrm{g}}$, Luca Deiana ${ }^{\mathrm{b}}$ \\ ${ }^{\text {a } F N R S-G e ́ D A P, ~ G r o u p e ~ d ' E t u d e s ~ d e ~ D e ́ m o g r a p h i e ~ A p p l i q u e ́ e, ~ U n i v e r s i t e ́ ~ C a t h o l i q u e ~ d e ~ L o u v a i n, ~ L o u v a i n-l a-N e u v e, ~ B e l g i q u e ~}$ \\ ${ }^{\mathrm{b}}$ Institute of Clinical Biochemistry, University of Sassari, Italy \\ ${ }^{\mathrm{c}}$ UMR Géographie-cités, University Paris 7, France \\ ${ }^{\mathrm{d}}$ Longitudinal Studies Section. Clinical Research Branch, National Institute on Aging, Baltimore, MD, USA \\ ${ }^{\mathrm{e}}$ Laboratory of Clinical Epidemiology, Geriatric Department, Italian National Research Centre on Aging (INRCA), Firenze, Italy \\ ${ }^{\mathrm{f}}$ Internal Medicine Unit, Azienda Ospedale-Università di Padova and University of Sassari, Italy \\ ${ }^{\mathrm{g}}$ Department of Experimental Pathology and C.I.G., University of Bologna, and INRCA, Department of Gerontological Research, Ancona, Italy
}

Received 6 May 2003; accepted 22 June 2004

Available online 9 August 2004

\begin{abstract}
High prevalence and low female/male ratio for validated centenarians are observed in Sardinia and these findings appear to be thus far unique to this island. Moreover a specific region on the island is characterized by exceptional male longevity. We calculated the extreme longevity index (ELI), defined as the percentage of persons born in Sardinia between 1880 and 1900, who became centenarians. A gaussian smoothing method was used in order to identify the so-called 'Blue Zone', where longevity is concentrated in the central-eastern part of the island and covers all the mountainous areas of central Sardinia. The estimated life expectancy in the 'Blue Zone' is longer than in the remaining territory of the island especially for men and the male to female ratio among centenarians born in this area is 1.35 compared to 2.43 in the rest of Sardinia. The specific mechanism by which persons living in this territory were more likely to reach extreme longevity remains unknown but it is interesting to note that most of the 'longevity hot spots' identified in various regions of the world over the years have been located in mountainous geographical areas even if none of these longevity regions have been fully validated. An alternative and interesting hypothesis is that the high rate of inbreeding determined by frequent marriages between consanguineous individuals and low immigration rates have progressively decreased the variability of the genetic pool and facilitated the emergence of genetic characteristics that protect individuals from diseases that are major causes of mortality particularly in older individuals. Given the exceptionally high prevalence of male centenarians in the 'Blue Zone', it is reasonable to assume that either the environmental characteristics or the genetic factors, or both, exert their favorable effect more strongly in men than in women. Thus, the mechanism involved may be modulated by the hormonal milieu, or may be associated with genes located in the sex chromosomes.
\end{abstract}

(c) 2004 Elsevier Inc. All rights reserved.

\section{Introduction}

Although it is widely recognized that life expectancy is influenced by a combination of genetic and environmental factors, it is still unknown whether specific characteristics of the natural or cultural environment may facilitate

\footnotetext{
* Corresponding author: Address. GéDAP, UCL, Bd. Devreux 6, 6000 Charleroi, Belgium. Tel.: +01-32-494425140; fax: +01-32-71202505. www.gedap.ucl.ac.be

E-mail address: poulain@sped.ucl.ac.be (M. Poulain).
}

the emergence of extreme longevity. In a study recently performed in Sardinia, Italy (Deiana et al., 1999), we found that the prevalence of centenarians was higher than in other European countries (16.6 per 100,000 inhabitants compared with 10 per 100,000 ), and that the female/male ratio was $2: 1$, substantially lower than the ratio reported by any previous study (generally more than 5:1, Table 1). High prevalence and lower female/male ratio were particularly evident in Nuoro, the most remote and mountainous regions among the four Sardinian provinces. These findings were remarkable but also suspicious since all previous reports on 
Table 1

Comparative figures on centenarian prevalence and sex ratio

\begin{tabular}{llll}
\hline $\begin{array}{l}\text { Countries } \\
\text { and regions }\end{array}$ & Date & $\begin{array}{l}\text { Prevalence (number } \\
\text { of living centenar- } \\
\text { ians per 100.000 } \\
\text { inhabitants) }\end{array}$ & $\begin{array}{l}\text { Sex ratio } \\
\text { (among living } \\
\text { centenarians } \\
\text { females/males) }\end{array}$ \\
\hline Belgium & January 1st 2002 & 10.5 & 7.08 \\
Denmark & July 1st 2002 & 10.4 & 6.27 \\
Sweden & January 1st 2003 & 12.6 & 5.64 \\
Italy & January 1st 2001 & 14.1 & 3.80 \\
Sardinia & January 1st 2001 & 16.6 & 2.70 \\
Nuoro & January 1st 2001 & 17.9 & 1.40 \\
province & & & \\
\hline
\end{tabular}

Source: statistical offices of respective countries.

exceptional long living populations concentrated in specific geographical areas have later been invalidated and explained by age misreporting or other errors in data collection (Koening, 2001, Jeune and Vaupel, 1995, 1999). Moreover, the fact that these peculiar findings were obtained in the Sardinian population is particularly interesting since Sardinians remained genetically isolated for a number of centuries and Sardinia experienced no immigration in recent history (Cavalli-Sforza et al., 1994). Moreover, the living habits in Sardinia have remained almost constant over the years, particularly in some parts of the island, where strong cultural and anthropological traditions are still present.

The major aims of the present study were: (1) to confirm the high prevalence and the unexpected low female/male ratio of centenarians in Sardinia, using multiple information sources; (2) to test the hypothesis that the geographical distribution of centenarians in Sardinia is non-random, and that a geographic area exists, where the population is characterized by exceptional longevity of men.

\section{Methods}

To validate the age of the centenarians identified in the AKEA $^{1}$ study (Deiana et al., 1999; Poulain et al., 2000), we first visited the Registry Office of the 40 municipalities where we had originally found the highest prevalence of centenarians and identified the oldest centenarians. To identify possible inconsistencies, we checked carefully the original documents and collected additional data from the birth register, the marriage register and the death register as well as from the population register (anagrafe).

The area with the highest concentration of centenarians could not be simply identified by grouping all municipalities with the highest percentage of the centenarians among the residents. In fact, the percentage of living centenarians

\footnotetext{
${ }^{1}$ AKEA is an acronym extracted from the Sardinian traditional wisk A KENT ANNOS that means approximatively "Health and life up to 100 ".
}

can be largely influenced by migrations and changes in the structure of the population over the century. As an alternative, we calculated the extreme longevity index (ELI), defined as the percentage of persons born in Sardinia between 1880 and $1900^{2}$, who became centenarians. This index, traditionally used in historical demography, conveys information on the probability that a person born in a given place becomes a centenarian. Moreover, the ELI is more stable and reliable than the simple one-year prevalence, because the number of centenarians used in the calculation is much higher. The ELI may be slightly underestimated because some newborns of the 1880-1900 cohorts emigrated out of Sardinia and could have become centenarians outside the island. Additionally, as we considered only the centenarians who were born in Sardinia, overestimation of ELI due to immigration is very unlikely.

To calculate ELI values for the 377 Sardinian municipalities, we used two types of data:

(1) statistics provided by the Italian National Statistical Institute (ISTAT) on the number of births that occurred in all Sardinian municipalities for the years 1880 $1900^{3}$,

(2) information collected in death registers of all municipalities on the place of birth of all centenarians who died during the years 1980-2000 or were alive in 2001.

Thereafter, the ELI for a given municipality was obtained by comparing the number of centenarians born in this municipality to the number of births that occurred in the same municipality from 1800 to 1900 included. Accordingly, when calculating the ELI index we did not assume that centenarians lived and died, where they were born, as it is usually done when calculating the usual centenarian prevalence.

To test the hypothesis that the geographical distribution of centenarians in Sardinia is non-random and that a peculiar geographic area could be identified, where ELI is consistently and significantly higher than in the whole of Sardinia, we used a spatial deterministic model (Grasland, 2000; Rogerson, 2001). Specifically, we tested the hypothesis that municipalities with high ELI and municipalities with low ELI are organized in clusters and that in the high ELI cluster all the municipalities with ELI higher than the average ELI for Sardinia would be spatially adjacent to cover a specific territory. To eliminate some random error, we did not include municipalities with high ELI but completely surrounded by

\footnotetext{
${ }^{2}$ In order to get a larger number of centenarians we decided to start with the cohort born in 1880 and included all subsequent generations up to 1900 included, where the latest centenarians could be found at the time of the research.

${ }^{3}$ Please note that some changes have occurred in the delimitation of municipality territory and moreover new municipalities were created as there were only 366 at the end of the 19th century.
} 
municipalities with low ELI, and included municipalities with low ELI but which were completely surrounded by municipalities with high ELI.

We estimated the difference between the number of centenarians born in the municipality $i, X(i)$, and the expected theoretical number of centenarians for the same municipality, $X^{\prime}(i)$. Based on the number of births between 1880 and 1900, $P(i)$, and the average ELI for the whole Sardinian population $X_{\mathrm{tot}} / P_{\mathrm{tot}}=0.00219$ (1132 centenarians per 516,276 newborns), as follows:

$X_{i}^{\prime}=P_{i} \cdot\left(X_{\mathrm{tot}} / P_{\mathrm{tot}}\right)=P_{i} \times 0.00219$

Meaningful, positive differences between specific municipalities and the whole of Sardinia were identified using the chi-square distance between theoretical and observed numbers of centenarians as follows:

$\mathrm{Chi}^{2}(i)=\left[X_{i}^{\prime}-X_{i}\right]^{2} / X_{i}^{\prime}$

This test is valid assuming that the expected number of centenarians in the municipality is larger than five. Based on the average probability that a newborn would become a centenarian, we calculated that a minimum number of 2283 newborns would be required to fulfill this condition and obtain a $\mathrm{Chi}^{2}>3.841$. None of the 377 Sardinian municipalities met these two conditions. To overcome this problem, we used a multiscalar smoothing method based on Gaussian neighborhood distribution (Grasland et al., 2000) that allows the study of the spatial concentration of centenarians as a continuum, and is not limited by the division of the Sardinian territory into 377 municipalities. The first step was to select the optimum scale in

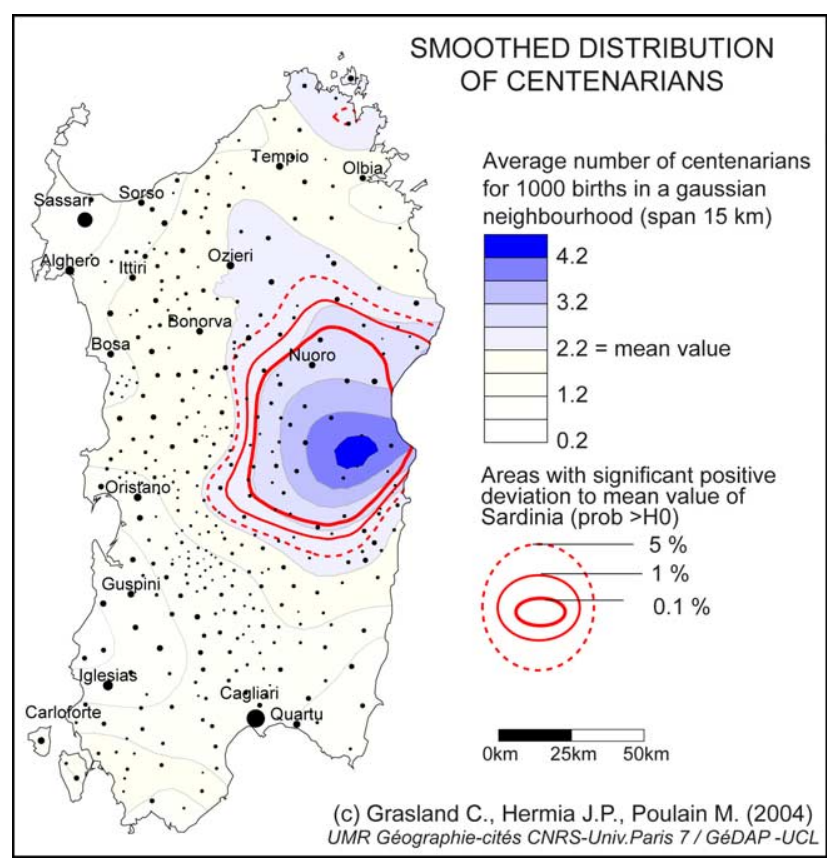

Fig. 1. Mapping significant positive differences between observed number of centenarians and theoretical numbers based of average Sardinian value with Gaussian smoothing method and $15 \mathrm{~km}$ distance. the Gaussian neighborhood distribution that would provide the best compromise between sufficiently large sample sizes and integrity of the information on the spatial distribution of centenarians. We found that a $15-\mathrm{km}$ Gaussian smoothing was large enough to capture the required minimal number of newborns without loosing too much information on the spatial variation. Using this method, we produced a map, where the concentration of centenarians is depicted as an area shaded in different colors, similar to the isobars in a weather map (Fig. 1). On this map, the intensity of the color blue is proportional to the value of ELI. The computed value in a given point is, in fact, the value related to the $15-\mathrm{km}$ neighborhood of this point. For a given point $i$ (not necessarily a municipality center) the Gaussian smoothing method is based on the following formulas, where $\delta$ is the smoothing distance:

\section{Observed potential for centenarians in a Gaus-} sian surrounding with distance $\delta$

$$
X(i, \delta)=\Sigma j X_{j} \cdot \exp \left(\alpha \cdot D_{\mathrm{ij}}^{2}\right) \text { with } \alpha=\ln (0.5) / \delta^{2}
$$

Observed potential for births in a Gaussian surrounding with distance $\delta$

$$
P(i, \delta)=\Sigma j P_{j} \cdot \exp \left(\alpha \cdot D_{\mathrm{ij}}^{2}\right) \text { with } \alpha=\ln (0.5) / \delta^{2}
$$

Theoretical potential for centenarians in a Gaussian surrounding with distance $\delta$

$X^{\prime}(i, \delta)=P(i, \delta) \times X_{\text {tot }} / P_{\text {tot }}$

Chi-2 distance between observed and theoretical potential for centenarians in the Gaussian surrounding

$$
\mathrm{Chi}^{2}(i, \delta)=\left[X^{\prime}(i, \delta)-X(i, \delta)\right]^{2} / X^{\prime}(i, \delta)
$$

\section{Corresponding Gaussian smoothed value of} ELI

$$
\mathrm{ELI}(i, \delta)=X(i, \delta) / P(i, \delta)
$$

Therefore, the map appears continuous. Additionally, the red isoclines are related to $\mathrm{achi}^{2}$ test of the null hypothesis, $H_{0}$ : the observed number of centenarians born in the neighborhood of a point is not significantly higher than the expected value according to the average value for Sardinia. In other words, we test if the number of births located in the $15 \mathrm{~km}$ neighborhood and the number of centenarians born in the same neighborhood are sufficiently high to reject the $H_{0}$. Determining the ELI is not sufficient because a high value of ELI could be obtained on a small sample and could therefore be related to random variations. Alternatively, a smaller positive deviation of the ELI could be significant if it is measured in an area, where the number of newborns is large.

From this first map, we estimated a second map based on contiguous municipalities, using the assumption that 
the inclusion of a given municipality is determined by the value of ELI calculated for all persons and centenarians born within this municipality, the distance considered being large enough to reach a significant value for ELI. The need to express the map in terms of municipalities comes from the fact that geographical, cultural and socio-economic information are aggregated by municipality.

The great advantage of the Gaussian smoothing method (compared to a direct observation of municipality values or to an aggregation of municipalities) is that (i) the biases related to the shape and size of territorial divisions is reduced and that such a method allows for the selection of the best compromise between sample size of the neighborhoods and the variability of the spatial distribution, and (ii) it gives the possibility to test $H_{0}$ on a spatial sample of sufficient size (Tobler, 1969; Grasland et al., 2000).

\section{Results}

\subsection{Age validation}

The ages of the centenarians previously identified and described in the AKEA study (Deiana et al., 1999) were all confirmed, with only one exception. A female centenarian who, according to the Death Registry of Villagrande municipality, died in 1985 at 110 years, but was in fact her younger sister, born 22 months later (Poulain et al., 2000) and therefore a true age was 107 years (approx. 107.8). These results confirmed the previously reported high prevalence and relatively low female/male ratio of centenarians in Sardinia (2:1), particularly in the Nuoro province (1:1).

\subsection{Geographical mapping of Sardinian longevity using the extreme longevity index (ELI)}

For the whole Sardinian population, the average value of ELI was 0.00219 (1132 centenarians divided by 516,276 newborns between 1880 and 1900). The results obtained by applying the multiscalar smoothing method to the geographical distribution of the ELI, suggested the existence of a geographic area characterized by a higher prevalence of exceptional longevity. This area is represented in blue shading in Fig. 1. The corresponding map based on aggregation of municipalities is presented in Fig. 2 and was defined as the 'Blue Zone' because in the course of the analysis it was originally delineated using a blue marker. The main area, where exceptional longevity is concentrated is located in the central-eastern part of the island (south-east of the Nuoro province) and covers all the mountainous areas of central Sardinia. The southwest portion of the island, as well as the main urban areas of Cagliari, Sassari, Olbia, and Oristano, are not included. Based on the level of ELI, the 'Blue Zone' can be further subdivided in order to identify a more

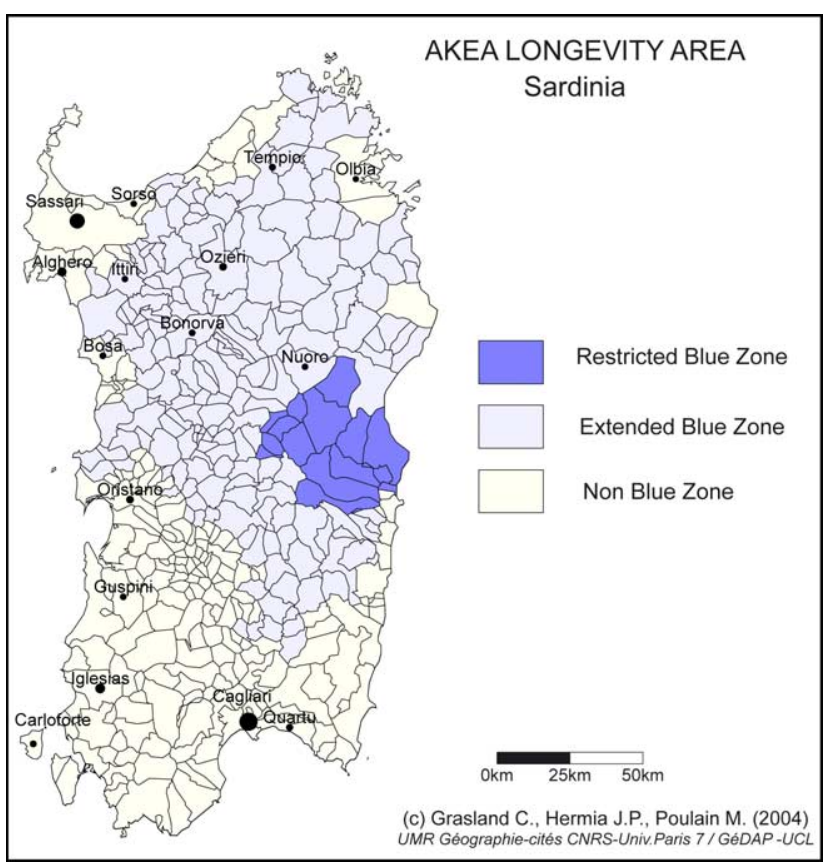

Fig. 2. Final shaping of the 'Blue Zone'or Extended Blue Zone (EBZ) including the Restricted Blue Zone (RBZ), both as a cluster of contiguous communes and using Gaussian smoothing method with appropriate distance for each municipality in order to get a significantly higher value of ELI.

restricted zone (hereon indicated as 'Restricted Blue Zone' or RBZ).

In this limited area, 91 persons, (47 men and 44 women) became centenarians of the 18,000 who were born in the area between 1880 and 1900. This is three-fold the number of centenarians expected based on the Sardinian average. For the whole 'Blue Zone' (indicated further as 'Extended Blue Zone' or EBZ), within the same 21 years birth cohort, 631 centenarians (269 men and 362 women) were born in the EBZ among a total of 240,000 newborns. This number is $50 \%$ higher than expected based on the Sardinian average. Thus, while more than half of the persons who were born in Sardinia between 1880 and 1900 and subsequently became centenarians were born in the EBZ, currently, less than one quarter of the Sardinian population lives in this region.

\subsection{Major characteristics of the 'Blue Zone'}

Major characteristics of EBZ and RBZ, in comparison to non-BZ and total Sardinia are presented in Table 2. Mortality in the EBZ was lower and estimated life expectancy was longer than in the remaining territory of the island especially for men. The sex ratio is 1.35 in the EBZ compared to 2.43 in the rest of Sardinia and, remarkably, there are more male than female centenarians in the RBZ (47 males and 44 females, sex ratio= $0.94)$. 
Table 2

Compared characteristics of the Restricted Blue Zone, the Extended Blue Zone and the non Blue Zone and the whole Sardinia ${ }^{a}$

\begin{tabular}{|c|c|c|c|c|}
\hline Variables & $\begin{array}{l}\text { Restricted blue zone } \\
\text { (RBZ) }\end{array}$ & $\begin{array}{l}\text { Extended blue zone (EBZ } \\
\text { including RBZ) }\end{array}$ & Non blue zone & Total Sardinia \\
\hline Population 2001 & 42,113 & 432,475 & $1,199,405$ & $1,631,880$ \\
\hline Area (sq km) & 1559 & 13,053 & 11,038 & 24,090 \\
\hline Population density 2001 & 27.0 & 33.4 & 107.7 & 67.7 \\
\hline Number of communes & 15 & 188 & 189 & 377 \\
\hline Average altitude & 588 & 417 & 142 & 280 \\
\hline Births $1880-1900$ & 17,865 & 239,439 & 276,837 & 516,276 \\
\hline Centenarians $1880-1900$ & 90 & 635 & 497 & 1132 \\
\hline Extreme longevity index (ELI) & 509 & 264 & 181 & 219 \\
\hline Male centenarians $1880-1900$ & 47 & 269 & 146 & 415 \\
\hline Female centenarians $1880-1900$ & 44 & 362 & 355 & 717 \\
\hline Male longevity index & 512 & 218 & 103 & 156 \\
\hline Female longevity index & 506 & 311 & 264 & 286 \\
\hline Sex ratio for centenarians $1880-1900$ & 0.936 & 1.346 & 2.432 & 1.728 \\
\hline Male life expectancy at birth $(1982-1998)^{b}$ & 75.0 & 74.3 & 73.9 & 74.0 \\
\hline Male life expectancy at $60(1982-1998)^{\mathrm{b}}$ & 20.9 & 20.3 & 19.3 & 19.4 \\
\hline Male life expectancy at $80(1982-1998)^{\mathrm{b}}$ & 8.7 & 8.2 & 7.3 & 7.5 \\
\hline $\begin{array}{l}\text { Female life expectancy at birth } \\
(1982-1998)^{\mathrm{b}}\end{array}$ & 82.2 & 80.7 & 80.5 & 80.5 \\
\hline Female life expectancy at $60(1982-1998)^{b}$ & 25.9 & 23.7 & 23.3 & 23.4 \\
\hline Female life expectancy at $80(1982-1998)^{b}$ & 11.1 & 8.7 & 8.3 & 8.3 \\
\hline Population variation 1961-2011 & $-9.4 \%$ & $-11.0 \%$ & $28.5 \%$ & $15.0 \%$ \\
\hline Average size of household & 3.12 & 3.02 & 3.19 & 3.14 \\
\hline Average number of rooms per housing & 6.05 & 6.24 & 5.80 & 5.93 \\
\hline Work or study in commune (p 100) & $37.5 \%$ & $40.2 \%$ & $41.0 \%$ & $40.7 \%$ \\
\hline Hospital beds per 10,000 inhabitants & 0 & 43.0 & 68.4 & 61.5 \\
\hline TV per 100 inhabitants & $23.0 \%$ & $26.0 \%$ & $25.3 \%$ & $25.5 \%$ \\
\hline Telephone per 100 inhabitants & $25.5 \%$ & $28.7 \%$ & $30.6 \%$ & $30.1 \%$ \\
\hline Car per 100 inhabitants & $36.6 \%$ & $39.5 \%$ & $46.4 \%$ & $44.5 \%$ \\
\hline
\end{tabular}

${ }^{a}$ Data are based on our own calculations or by aggregating ISTAT data at municipality level.

${ }^{\text {b }}$ Life expectancy calculated, by Graziella CASELLI and Rosa Maria LIPSI based on ISTAT data (Caselli and Lipsi, 2003).

From the geographical point of view, the 'Blue Zone' is a mountainous region, which was quite remote and difficult to access until a few decades ago. Such a geographic situation discouraged immigration, favored inbreeding, intermarriage and consanguinity, thus decreasing the variability of the genetic pool. For many years an agricultural economy, pastorizia, and livestock breeding represented the only sources of income. The inhabitants of this area maintain the cultural and anthropological characteristics typical of the ancient traditions, which are favored by local authorities. Accordingly, nutrition and other lifestyle habits are rather conserved and healthy.

\section{Discussion}

Two findings particularly stand out from this study: this work confirms previous research indicating the relatively high prevalence of centenarians in Sardinia and that there is an unusually low ratio of female to male centenarians, particularly in one isolated region of the island. This study provides solid evidence that the geographic distribution of longevity in Sardinia is not homogeneous, and that a specific geographic area exists, where the probability of becoming a centenarian has been significantly higher than in the remaining territories of the island. Interestingly, the area of extreme longevity is located in the mountainous geographical region, which has been relatively isolated until recent times. The specific mechanism by which persons living in this territory were more likely to reach extreme longevity remains unknown but it is interesting to note that most of the 'longevity hot spots' identified in various regions of the world over the years were located in mountainous geographical areas even if none of these longevity regions have been fully validated. The peculiar climatic and cultural features of this zone including nutrition and life styles of the population can be considered as shared characteristics favoring extreme longevity in the resident population, therefore facilitating the emergence of longlived individuals.

An additional and interesting hypothesis is that the high rate of inbreeding determined by frequent marriages between consanguineous individuals and low immigration rates have progressively decreased the variability of the genetic pool and facilitated the emergence of genetic 
characteristics that either do not predispose for and/or might actually protect individuals from diseases that are major causes of mortality particularly in older individuals (Tan et al., 2001). Given the exceptionally high prevalence of male centenarians in the 'Blue Zone', it is reasonable to assume that either the environmental characteristics or the genetic factors, or both, exerted their favorable effect more strongly in men than in women. Thus, the mechanism involved may be modulated by some physiology specific to men (e.g. hormones), or may be associated with genes located in the sex chromosomes. Alternatively, it is also possible that the factors contributing to high longevity acted similarly in men and women, but some environmental or cultural factor determined a higher mortality in older women compared to older men. Some features of the Sardinian culture, where the role of men in the family was strongly predominant may suggest that the existence of such a sex-specific selection process cannot be excluded (Da Ré et al., 1984).

One of the most important strengths of our study is the validity of the data on the age of centenarians, which were cross-validated using at least three independent sources of information. Compared with the data collected in the AKEA database, in the validation study we found only one trivial discrepancy. As mentioned in the introduction, this is important because previous claims of 'longevity hot spots' were generally disqualified by subsequent, more rigorous data collection.

Additionally, we use the ELI for the assessment of longevity instead of the traditional measure of prevalence of centenarians and this innovative tool makes our analysis particularly robust and reliable. This index is particularly adequate in Sardinia where the population experienced large migration flows on both internal and international levels. We suggest that the analytical approach based on the ELI should be used in other studies on centenarians in order to develop more reliable international comparisons on a worldwide scale. Even using the ELI that considers all the centenarians who lived in a 20 -year period, we lacked the statistical power to perform a crude aggregation of municipalities, and we had to use a smoothing method based on statistical modeling of predefined Gaussian neighborhoods. This method provided clearly interpretable information. Further refinement and wider application of this method in studies on the geographical distribution of longevity is warranted.

The characterization of the 'Blue Zone' for environmental factors that might influence longevity was limited to altitude, socio-economic status and cultural background. This information is easily accessible at the municipality level but are certainly inadequate to capture the critical factors that allowed the emergence of a higher number of centenarians in the 'Blue Zone', compared to the rest of the island. The direct collection of historical and current information based on specific scientific hypothesis should be attempted in the future.
In conclusion, we demonstrated that the high prevalence and the peculiarly low female/male ratio of centenarians in Sardinia are not homogeneously distributed across the entire island territory. Future studies focusing on environmental uniqueness of the 'Blue Zone' and on the genetic characteristics of its inhabitants may shed new light on the mechanism that influences longevity in humans.

\section{Acknowledgements}

The research presented here was financed by the US National Institute on Aging, subcontract with Duke University n. 03-SC-NIH-1027, by funds from the MaxPlanck Institute for Demographic Research (MPIDR) in Rostock, Germany, and by The Autonomous Region of Sardinia, Italy. We gratefully acknowledge the support from the Italian National Statistical Institute (ISTAT) and thank especially Dr Marianna Tosi (Centro Informazione Statistica, ISTAT, Cagliari, Sardinia) who supplied us with most of the Sardinian demographic data at municipality level. We are particularly indebted to the Civil State Registry Office of all Sardinian municipalities for providing access to the birth, marriage, and death registers covering the period from 1867 to 2001. We thank Prof Graziella Caselli and Dr Maria Rosa Lipsi from the Dept. of Demographic Sciences, University 'La Sapienza', Rome, Italy for the calculation of life expectancy in the Sardinian population. A particular thank to Dr Alessandra Errigo and Dr Antonella Budroni for their skillful assistance in the collection of archival data.

\section{References}

Caselli, G., Lipsi, R., 2003. Geographical Mortality Differences and Trends for the Elderly in Sardinia, 1982-1998. Dipartimento di Scienze Demografiche, Roma.

Cavalli-Sforza, L.L., Menotti, P., Piazza, A., 1994. The History and Geography of Human Genes. Princeton University Press, Princeton, NJ.

Da Ré, M.G., Murru-Corriga, G., Cossu, S., 1984. Le travail des femmes dans la Sardaigine traditionnelle, in Collectif, Les femmes et la question du travail, Lyon. Presses Universitaires De France, Paris, France, pp. 84-106.

Deiana, L., Ferrucci, L., Pes, G.M., Carru, C., Delitala, G., Ganau, A., Mariotti, S., Nieddu, A., Pettinato, S., Putzu, P., Franceschi, C., Baggio, G., 1999. AKEntAnnos. The Sardinian study of extreme longevity. Aging Clinical and Experimental Research 11, $142-149$.

Grasland, C., 2000. Lissage cartographique et animation spatio-temporelle: quelques réflexions méthodologiques, Travaux de L'Institut de Géographie de Reims, 83-104.

Grasland, C., Mathian, H., Vincent, J.M., 2000. Multiscalar Analysis of discrete social phenomena: Statistical problems and political consequences. Statistical Journal of the United Nations 17, 157-188.

Jeune, B., Vaupel, J. (Eds.), 1995. Exceptional Longevity: From Prehistory to the Present. Odense Monographs on Population Aging, vol. 2. Odense University Press, Odense. 
Jeune, B., Vaupel, J. (Eds.), 1999. Validation of Exceptional Longevity. Odense Monographs on Population Aging, vol. 6, p. 249.

Koenig, R., 2001. Sardinia's mysterious male methuselahs. Science 291, 2074-2076.

Poulain, M., Pes, G.M., Carru, C., Baggio, G., Franceschi, C., Ferrucci, L., Deiana, L., 2000. The Validation of a Population of Exceptional Longevity in Sardinia. Paper presented at the IUSSP seminar on longevity held in Montpellier in 2000 (to be published).
Rogerson, P., 2001. A statistical method for the detection of geographic clustering. Geographical Analysis 33, 215-227.

Tan, Q., Yashin, A.I., Bladbjerg, E.M., de Maat, M.P., AndersenRanberg, K., Jeune, B., Christensen, K., Vaupel, J.W., 2001. Variations of cardiovascular disease associated genes exhibit sex-dependent influence on human longevity. Experimental Gerontology 36, 13031315.

Tobler, W.R., 1969. Geographical filters and their inverses. Geographical Analysis 1, 234-253. 